\title{
Comparative Study of cell Block Versus Centrifuged Smear Examination from Aspirates of Cystic Lesions
}

\author{
S.R. Niveditha ${ }^{1 *}$, Thejasvi Krishnamurthy ${ }^{1}$ and Sumitha Prakash ${ }^{2}$ \\ ${ }^{1}$ Department of Pathology, Kempegowda institute of Medical sciences, Bangalore, India \\ ${ }^{2}$ Department of Pathology, Rajarajeswari Medical College and Hospital, Bangalore, India
}

\begin{abstract}
Background: Cystic fluids encountered during routine FNA poses a diagnostic challenge to cytopathologists due to its low cell yield with high dispersal of cells on conventional centrifuged smears (CS). Cell Block (CB) technique enables retrieval of small tissue fragments from fluids, thereby providing scope for better morphology and material for ancillary techniques which help in improving the diagnosis.

Aim: To compare the efficacy of CB versus CS, in cyto-diagnosis of cystic lesions.

Methods: This observational study was conducted on a total of 50 fluid samples aspirated from cystic lesions during routine FNA and fluids aspirated peri-operatively from cystic ovarian lesions. Divided into two equal parts, one part was processed for CS and CB by Fixed Sediment Method and relevant immunohistochemistry was performed. CSs were categorized as positive for malignancy, benign diagnosis, Inadequate for opinion and suspicious for malignancy. CBs were categorized as; no material, Non-contributory (CS+, CB-), confirms the smear diagnosis and establishes a specific diagnosis. The comparison between CS and CB was analysed by Chi- square test \& kappa test.

Results: Out of the 50 cases, 35(70\%) were given a benign diagnosis, $10(20 \%)$ were positive for malignancy, 2(4\%) were suspicious and $3(6 \%)$ were inadequate for opinion on CS. In CB out of 50 cases, 29 of them confirmed/established a diagnosis and 21 cases were non diagnostic / non-contributory. CB gave an improved diagnosis in 2 out of $10(20 \%)$ malignant cases and 2 out of 35 (5.7\%) benign cases. $(\mathrm{p}$ value $=0.00054$, Kappa value $=0.34)$

Conclusions: CBs complemented CS, more so in malignant lesions by preserved architecture. Aspirates from multiple sites of the cystic lesions (with/without radiological assistance) pooled as one specimen yielded better material for CBs and ancillary techniques like histochemistry and IHC.
\end{abstract}

Keywords: Cystic Lesions, Cell Block, Centrifuged Smear, Fixed Sediment Method

\section{Introduction}

One of the constraints of conventional FNA smear is the limited material available for adjuvant diagnostic investigations. ${ }^{[1,2]}$ Cellblock technique has been applied to aspirated material ${ }^{[3]}$ and since then has been used increasingly to improve the diagnostic accuracy of FNA. ${ }^{[4,5]}$

Karnauchow et al were the first to emphasize that cell block technique could be used in thick tissue particles aspirated by FNA, which provided sufficient material for a good section, special stains and IHC. ${ }^{[3]}$ Some authors also tried needle washes of aspirates from solid lesions with considerable success. ${ }^{[2,5-10]}$

Following which many authors studied role of cell block in cystic fluid aspirates of jaw lesions, thyroid lesions, cystic lesions of head and neck and cystic pancreatic mucinous tumors. ${ }^{[11-16]}$

Most of these studies were limited to single organ or anatomical region. Therefore, we formulated a study to compare the efficacy of cell block by formalin fixed sediment method versus the conventional centrifuged smears, in studying all cystic aspirates encountered during routine FNA procedure. Additionally, intact cysts received for frozen sections were also aspirated (Peri-operative) and included in the study.

\section{Materials and Methods}

This observational study was carried out in the cytopathology division of the department of pathology at a tertiary care hospital, over a period of two months. A total of 50 fluid samples aspirated from cystic lesions during routine FNA and fluids aspirated peri-operatively from cystic ovarian lesions were included in the study. Data was collected in a pretested proforma. All fluids (irrespective of volume), aspirated in the laboratory were processed at the earliest. Due to technical reasons, if the fluids could not be processed immediately, they were stored in a refrigerator at $4^{\circ} \mathrm{C}$ and processed later. The fluids were examined grossly for volume, color and appearance and findings were noted. 
The fluids were divided into two equal parts. One part was kept for conventional cytology (centrifuged smear - CS) and the other part for cellblock (CB). ${ }^{[17]}$ For conventional smear, the fluid was centrifuged at $2500 \mathrm{rpm}$ for 10 minutes (REMI CENTRIFUGE) in plastic test tubes and supernatant decanted. Minimum of two thin smears were prepared from the sediment and PAP and H\&E staining were done.

The other portion of fluid specimen was processed by Fixed Sediment Method of Cellblock according to Nathan et $\mathrm{al}^{[18]}$ The fluid specimen kept aside for $\mathrm{CB}$, was fixed in ethanol formalin fixative ( 9 parts absolute alcohol \& 1 part $10 \%$ formalin) in the ratio of $1: 1$ for one hour. After fixation the specimen was centrifuged at $2500 \mathrm{rpm}$ for 10-15mins. Supernatant was poured off and sediment drained by inverting the tube on Whatman filter paper (No: 52, WR BALSTON LTD, $11 \mathrm{~cm}$ disc). The sediment was then wrapped in the same filter paper and processed in histokinette as routine histopathological specimen. Multiple thin sections of 4-5 micron thickness from paraffin blocks were obtained, stained with Haematoxylin and Eosin stain and examined microscopically. Based on the cytological findings, relevant immunohistochemistry was performed wherever necessary.

After studying all the available clinical data, based on morphology, the CS and CB were categorized as: ${ }^{[8]}$

\begin{tabular}{|l|l|}
\hline Centrifuged smear & Cell block \\
\hline Positive for malignancy & Non diagnostic / no material \\
Benign diagnosis & Non-contributory (CS+, CB-) \\
Inadequate for opinion & Confirms the smear diagnosis \\
Suspicious for malignancy & Establishes a specific diagnosis \\
\hline
\end{tabular}

Binomial distribution was performed to assess the comparison between conventional smear and cellblock. SPSS 20.0 for Windows software package (SPSS Inc., Chicago, IL, USA) was used for analysis by Chi- square test, kappa test. $\mathrm{P}<0.05$ was considered to be statistically significant.

Since this is a comparative study, for statistical purposes the CS and CB categories were grouped as:

$\mathrm{CS}=0$ (Positive for malignancy \& Suspicious for malignancy)

$\mathrm{CS}=1$ (Benign diagnosis \& Inadequate for opinion)

$\mathrm{CB}=0$ (Non diagnostic/ Non-contributory)

$\mathrm{CB}=1$ (Confirms/ Establishes diagnosis)

\section{Results}

Fifty (50) fluids from cystic lesions were included in the study, of which 37 belonged to fluids from routine FNAs while the remaining 13 belonged perioperative fluids. Among FNA fluids majority (27\%) were from breast lesions followed by lymphnodes (18.9\%). Eight (8) fluids grouped as miscellaneous included 4 cases of hepatic abscess, 2 from nape of neck swellings, 1-glabellar swelling and 1-palm swelling. Among the peri-operative all were from ovarian cysts (table 1).

Females $(68 \%)$ were majority most of them in the age froup of 40-60 yrs (table 2). Volume of the fluid aspirated was $>10 \mathrm{ml}$ in $80 \%$ of the fluids by FNA while perioperative ovarian cyst fluids, were upto $100 \mathrm{ml}$ in majority. On centrifugation of the fluids, good pellet formation was seen in $66 \%$ of cases.

On conventional smear (CS) examinaton, 70\%(35/50) were given a benign diagnosis, $20 \%(10 / 50)$ were positive for malignancy, $4 \%(2 / 50)$ were suspicious and $6 \%(3 / 50)$ were inadequate for opinion (table 3 ). Of the benign lesions majority were ovarian cysts (10/35) followed by cystic lesions in the breast (7/35). On CB preparation from these 35 fluids (benign on CS) smear diagnosis was confirmed in 57\% (20/35), while a specific/ improved diagnosis could be established in 2 cases (table 3). One case was of a breast aspirate diagnosed as benign breast disease on CS (fig 1,inset), however the CB of the same showed varying sized cysts surrounded by fibrosis and epitheliosis there by improving the diagnosis to fibrocystic disease (fig 1). The second case was of an ovarian neoplasm with cystic degeneration, was diagnosed as broad ligament leiomyoma with cystic change based on the scattered plump spindle cells on CS. CB of the same showed monotonous spindle cells with absence of whorling and hence was subjected to IHC for SMA which was negative(fig 2) improving the diagnosis to ovarian fibroma. (fig 2, inset). In the remaining 13 cases $\mathrm{CB}$ did not yeild material on $\mathrm{CB}$. Hence $\mathrm{CB}$ yeilded material in $22 / 50$ ie., $62.8 \%$ of benign cases.

Among the 10 cystic fluids which were positive for malignancy by $\mathrm{CS}$, in 5 cases $\mathrm{CB}$ confirmed the diagnosis. In 2 cases, $\mathrm{CB}$ established a specific diagnosis (table 2).

They were: 1. Fluid from a cervical lymph node, on CS suggested metastatic poorly differentiated carcinoma which on $\mathrm{CB}$ showed squamous pearl, CK and EMA positivity on IHC thereby establishing diagnosis of metastatic squamous cell carcinoma (fig 3).

2. Fluid from a cystic ovarian mass was reported as positive for malignancy on $\mathrm{CS}$, which on $\mathrm{CB}$ showed papillary clusters with pleomorphic cell morphology establishing a diagnosis of papillary cystadenocarcinoma - ovary. In the remaining three cases $\mathrm{CB}$ material was non-contributory. Hence in positive for malignancy, $\mathrm{CB}$ yielded material in $70 \%(7 / 10)$ of cases.

Among the two cases which were diagnosed as suspicious for malignancy on $\mathrm{CS}, \mathrm{CB}$ material did not contribute to either confirming or establishing the CS diagnosis. 
Of the 50 cases, three of them were inadequate for opinion even on CS. Of the remaining 47 having enough material on CSs, 29(61.7\%)of them confirmed/established a diagnosis on $\mathrm{CB}$. $\mathrm{CB}$ gave an improved diagnosis in 2 out of 10
(20\% ) malignant cases and 2 out of $35(5.7 \%)$ benign cases (table4,5). Chi square test yeilded 11.947 with a significant $\mathrm{p}$ value of $0.00054(p<0.05)$.Kappa test yeilded a value of 0.34 suggesting a fair degree of aggreement between CS and CB.

Table 1.:Distribution of cases among cystic fluids $(n==50)$

\begin{tabular}{|c|c|c|}
\hline Type of cystic fluids & Site & Frequency (n) \\
\hline \multirow{4}{*}{ FNA } & Thyroid & 2 \\
\hline & Breast & 10 \\
\hline & Cervical lymph node & 7 \\
\hline & Salivary gland & 5 \\
\hline \multirow{9}{*}{ Miscellaneous } & Liver & 4 \\
\hline & Lung & 1 \\
\hline & Omental mass & 1 \\
\hline & Rib swelling & 1 \\
\hline & Inguinal swelling & 1 \\
\hline & Arm swelling & 1 \\
\hline & Palm swelling & 1 \\
\hline & Nape of the neck swelling & 2 \\
\hline & Glabellar region swelling & 1 \\
\hline Peri-operative & Ovary & 13 \\
\hline Total & & 50 \\
\hline
\end{tabular}

Table 2: Age and sex distribution.

\begin{tabular}{|c|c|c|c|}
\hline Age in yrs & Male & Female & Percentage \\
\hline $0-20$ & 0 & 1 & $2 \%$ \\
\hline $20-40$ & 7 & 9 & $32 \%$ \\
\hline $40-60$ & 3 & 20 & $46 \%$ \\
\hline $61-80$ & 3 & 7 & $20 \%$ \\
\hline Total & 13 & 37 & $100 \%$ \\
\hline
\end{tabular}

Table 3: Distribution of benign and malignant cases among cystic fluids

\begin{tabular}{|c|c|c|c|}
\hline Site & Benign & Malignant/suspicious & Total \\
\hline Thyroid & 2 & 0 & 2 \\
\hline Breast & 7 & 3 & 10 \\
\hline Lymph Node & 5 & 2 & 7 \\
\hline Salivary Gland & 3 & 0 & 3 \\
\hline Miscellaneous & 8 & 5 & 13 \\
\hline Peri-op ovary & 10 & 2 & 12 \\
\hline Total & $\mathbf{3 5}$ & $\mathbf{1 2}$ & $\mathbf{4 7}$ \\
\hline
\end{tabular}

\footnotetext{
*3 cases were inadequate.
}

Table 4: Cross tabulation of CS vs CB in fluids from cystic lesions

\begin{tabular}{|c|c|c|c|c|c|}
\hline \multirow{2}{*}{ CB category } & \multicolumn{2}{|c|}{ CS category } & \multicolumn{2}{c|}{ Total } \\
\cline { 2 - 6 } & $\begin{array}{c}\text { Positive for } \\
\text { malignancy }\end{array}$ & Benign & Inadequate & 2 & 18 \\
\hline $\begin{array}{c}\text { Non-diagnostic/no } \\
\text { material }\end{array}$ & 0 & 13 & 0 & 0 & 3 \\
\hline Non-contributory & 3 & 0 & 0 & 0 & 25 \\
\hline $\begin{array}{c}\text { Confirms } \\
\text { diagnosis }\end{array}$ & 5 & 20 & 0 & \\
\hline
\end{tabular}




\begin{tabular}{|c|c|c|c|c|c|}
\hline \multirow{2}{*}{ CB category } & \multicolumn{4}{|c|}{ CS category } & Total \\
\cline { 2 - 6 } & $\begin{array}{c}\text { Positive for } \\
\text { malignancy }\end{array}$ & Benign & Inadequate & suspicious \\
\hline $\begin{array}{c}\text { Establishes } \\
\text { diagnosis }\end{array}$ & 2 & 2 & 0 & 0 & 4 \\
\hline Total & 10 & 35 & $\mathbf{3}$ & $\mathbf{2}$ & 50 \\
\hline
\end{tabular}

Table 5: Summary of cystic fluids (malignant cases)

\begin{tabular}{|c|c|c|c|c|c|c|c|}
\hline $\begin{array}{c}\text { SI } \\
\text { No }\end{array}$ & $\begin{array}{c}\text { TYPE OF } \\
\text { FLUID }\end{array}$ & VOLUME & $\begin{array}{c}\text { PELLET } \\
\text { FORMATION }\end{array}$ & CS* & CB** & MORPHOLOGY & IHC \\
\hline 1 & FNA CERVICAL LN & $<10 \mathrm{ml}$ & + & 1 & 3 & Keratin pearl & - \\
\hline 2 & FNA CERVICAL LN & $<10 \mathrm{ml}$ & + & 1 & 4 & Clusters of cells & CK+ EMA+ \\
\hline 3 & FNA INGUINAL LN & $<10 \mathrm{ml}$ & + & 1 & 3 & Clusters of melanoma cells & - \\
\hline 4 & FNA BREAST & $<10 \mathrm{ml}$ & + & 1 & 3 & Clusters of cells & - \\
\hline 5 & FNA rib swelling & $<10 \mathrm{ml}$ & + & 1 & 3 & Cytoplasmic bridges & - \\
\hline 6 & FNA lung mass & $<10 \mathrm{ml}$ & + & 1 & 3 & Cell groups & - \\
\hline 7 & Cystic Ovarian mass & $>100 \mathrm{ml}$ & + & 1 & 4 & Papillary cluster & - \\
\hline 8 & Cystic Ovarian mass & $10-100 \mathrm{ml}$ & + & 1 & 2 & Non-contributory & - \\
\hline 9 & FNA BREAST & $<10 \mathrm{ml}$ & + & 1 & 2 & Non-contributory & - \\
\hline 10 & FNA OMENTAL MASS & $<10 \mathrm{ml}$ & + & 1 & 2 & Non-contributory & - \\
\hline 11 & FNA BREAST & $10-100 \mathrm{ml}$ & + & 4 & 1 & Non-diagnostic & - \\
\hline 12 & FNA arm swelling & $10-100 \mathrm{ml}$ & + & 4 & 1 & Non-diagnostic & - \\
\hline
\end{tabular}

CS* categories: $1=$ positive for malignancy, $2=$ Benign, $3=$ Inadequate for opinion, $4=$ suspicious for malignancy

$C B^{* *}$ categories: $1=$ non-diagnostic/nomaterial, $2=$ noncontributory, $3=$ confirms smear diagnosis, $4=$ Establishes specific diagnosis

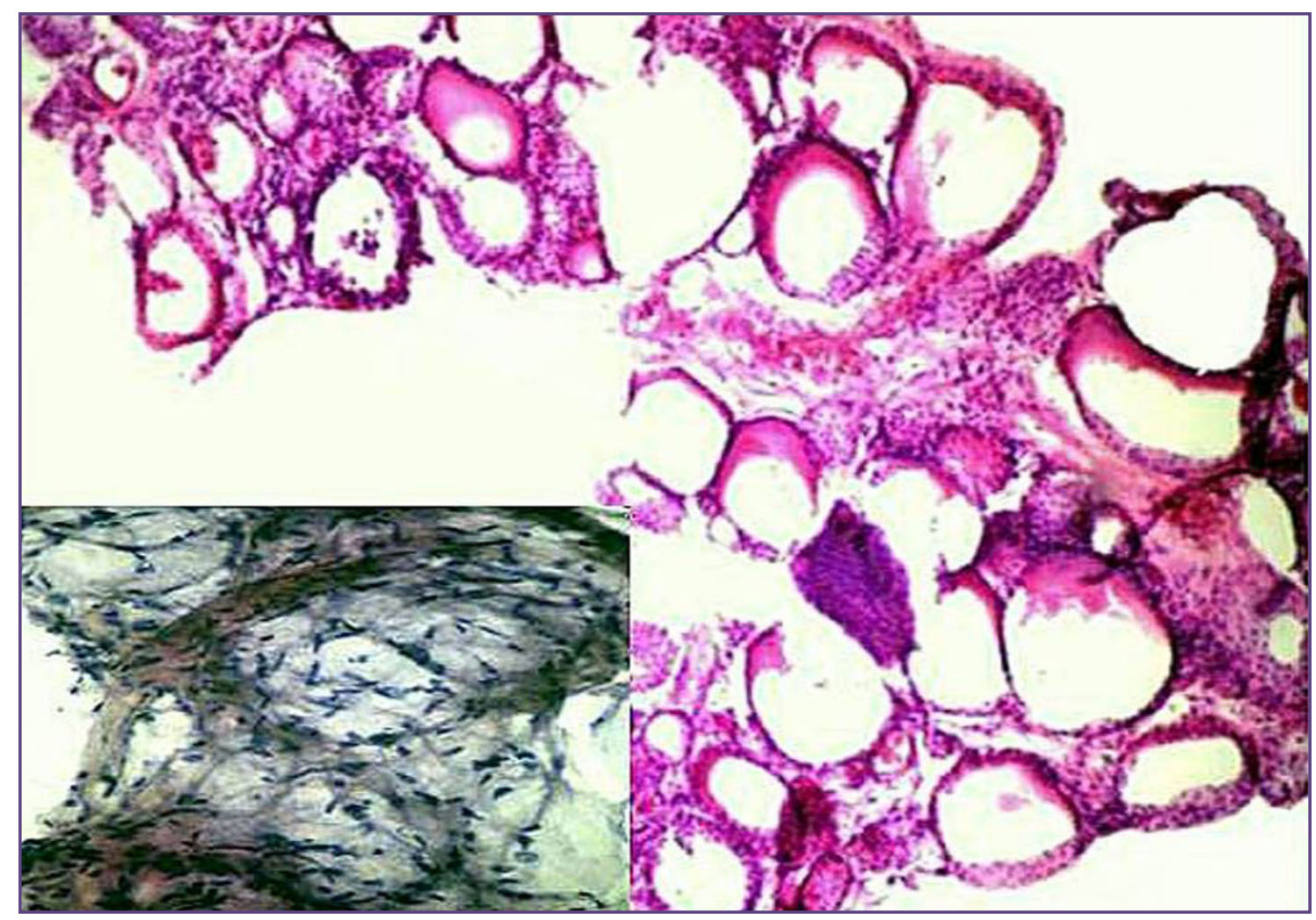

Fig. 1: CS on cystic fluid from breast showing only stromal fragments- PAP stain 40X(Inset) CB on cystic fluid from breast showing cysts surrounded by fibrosis- H\&E 10X. 


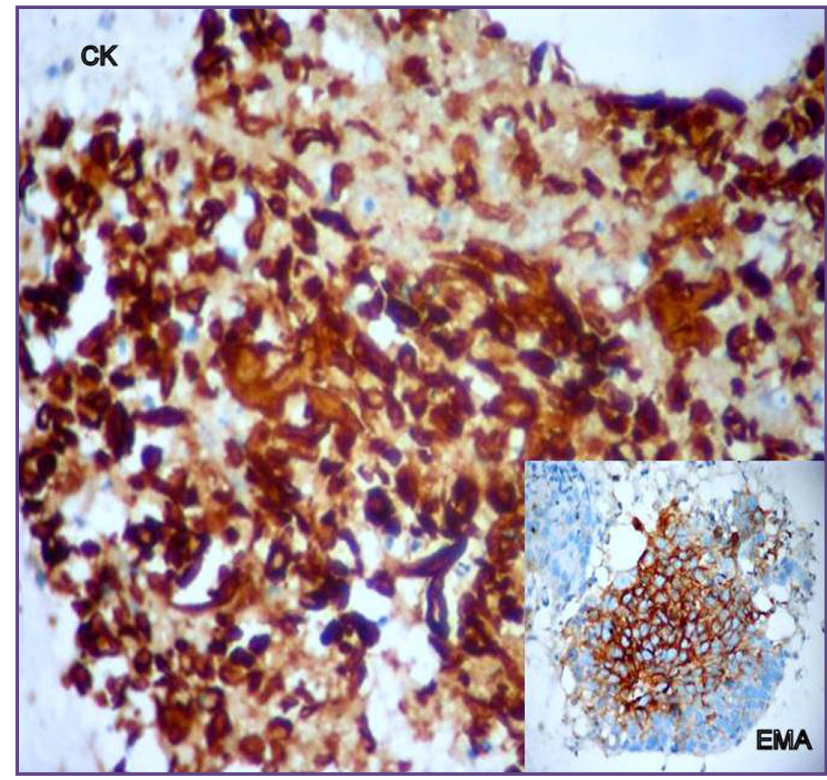

Fig. 2: CB on fluid from cystic ovarian mass showing cluster of spindle cells - (H\&E,400x) Inset- IHC on CB from cystic ovarian mass - SMA negative (IHC, DAKO, 400x).

\section{Discussion}

On many occasions, clinical and radiological examination can give a provisional diagnosis, which however needs to be confirmed /complemented by tissue diagnosis. The commonest procedure for obtaining material for tissue diagnosis is either an excisional or incisional biopsy. Biopsy may be a complex procedure at some sites such as maxilla-mandibular areas, oral cavity etc. and also difficult in patients with some systemic morbid conditions. ${ }^{[11,12]}$ In such situations FNA may be the only alternative. However, in aspirates of cystic lesions where the cell numbers are generally less, the technique of cell block is a great advantage. On FNA of cystic lesions, when aspirated fluid is centrifuged, concentration of lesion-typical cells with decreased cell dispersion occurs and improves diagnosis. ${ }^{[19}$, ${ }^{20]} \mathrm{CB}$ procedure of such concentrated material, could replace biopsy thereby simplifying the diagnostic process. ${ }^{[10-12]}$

Moreover, material obtained by FNA of some lesions accessed through newer procedures like endoscopy etc., maybe so little that $\mathrm{CB}$ on the little material gives added advantage of architectural details and additional material for special stains.

Some Cystic lesions of the jaw have similar clinical and radiological findings. For example, Keratocystic Odontogenic tumors (KOTs) are developmental neoplastic lesions which need to be differentiated from aggressive lesions like ameloblastoma, as their treatment varies. Hence a good pre-operative diagnosis will help the clinician in therapeutic planning for such lesions and therefore ancillary

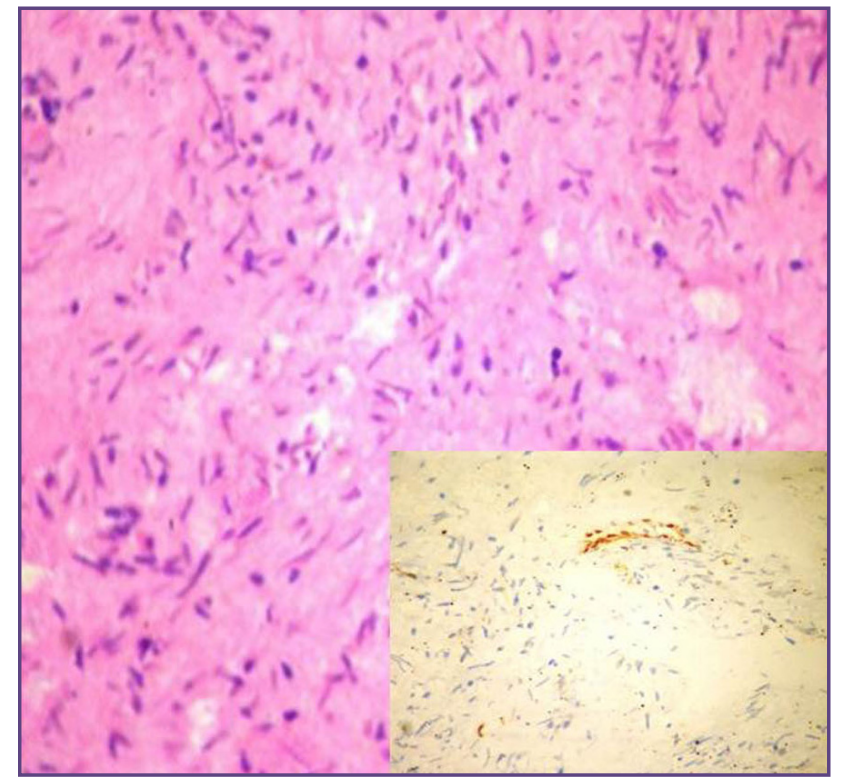

Fig. 3: CK and EMA(inset) positivity on CB from cystic aspirate of cervical lymph node with metastatic carcinoma (IHC,DAKO, 400x).

techniques like CB becomes important. ${ }^{[11]}$ Oenning and Rivero et al, studied series of 17 and 33 cystic jaw lesions respectively, by aspiration and processing the material by the $\mathrm{CB}$ technique. ${ }^{[1,12]}$ Both were of the opinion that cell block technique is a complementary method which is simple, fast and cost-effective and can eliminate the need for incisional biopsy.

Hegazy et al studied 85 thyroid lesions by both CS and CB methods. ${ }^{[13]}$ Their series included one thyroglossal cyst and two cases of branchial cleft cysts along with Cystic nodules in 5 cases (colloid goiters). Cystic degeneration may be observed in both benign and malignant thyroid nodules and the approximate malignancy rate within cystic thyroid nodules is $10 \%$. They were of the opinion that conventional FNA of cystic nodules has a high rate of nondiagnostic and false negative results and CB may resolve this problem. In their series, inadequacy of smears was $15 \%$ but cell block reduced it to (5.8. \%). They also found that $\mathrm{CB}$ gave good inter-relation of the cells together, forming follicles or papillae with the nuclear features becoming more clear and obvious. Their study showed CBs with an overall sensitivity of $91.6 \%$ and specificity of $97.2 \%$ among thyroid aspirates. ${ }^{[13]}$ In our study we had 2 cases of cystic thyroid nodules diagnosed as colloid goiters on CS later confirmed by $\mathrm{CB}$ with better morphology.

Xiao et al studied 17 cases of cystic pancreatric mucinous tumors on FNA and found that the yield of diagnostic cells was typically low. ${ }^{[16]}$ Specific diagnosis was supported by cellblock and/or increased CEA. Narayan et al reported a 
case of papillary cystic variant of acinic cell carcinoma in which $\mathrm{CB}$ aided in an accurate pre-operative diagnosis. ${ }^{[21]}$ When cell count is low in CS smears it is difficult to discern whether it is a cyst or cystic degeneration. Our study had three aspirates of salivary gland diagnosed as benign lesions on CS, but CB helped in segregating them into two cases of pleomorphic adenoma with cystic degeneration and one case of true cyst later confirmed by histopathology. A specific diagnosis helped the surgeon in planning the surgery. Similarly in cystic breast aspirates, especially from malignant lesions, CB would help differentiating degenerative changes seen in cells(due to presence of exfoliated cells in fluids for long time) leading to false positive diagnosis, from anaplastic changes with the help from the surrounding architecture. Among the 10 breast aspirates 7 were benign on CS confirmed by CB. Remaining three were suspicious for malignancy on CS, of which only in one case $\mathrm{CB}$, confirmed the diagnosis.

In cystic lesions with infective etiology also, $\mathrm{CB}$ seems to complement the FNA /CS diagnosis. Kim et al reported $\mathrm{CB}$ in a case of hepatic hydatid cyst showing protoscolices, hooklets and fragments of laminated material along with inflammatory cells and amorphous necrotic debris complementing the CS diagnosis. ${ }^{[22]}$ In our study 4 cases of hepatic abscess were aspirated and CB confirmed the CS diagnosis. Multiple serial sections could be obtained from the respective CBs for special stains to rule out amoebic and fungal etiology. Two lymph node aspirates diagnosed as tubercular cold abscess on CS were confirmed by $\mathrm{ZN}$ stain on $\mathrm{CB}$ too, with an added advantage of quicker screening of AFB due to less cell dispersion on $\mathrm{CB}$.

Khurana et al studied 20 cases of squamous lesions in the neck by cell block. Their study group included 7 cases of atypical squamous cells which were suspicious of squamous cell carcinoma (SCC) on conventional smears, which were later confirmed as SCC by p53 staining on CB. ${ }^{[15]}$ Shaloo et al also shared similar experience in diagnosing recurrent SCC of oral cavity. ${ }^{[23]}$ They suggested that $\mathrm{CB}$ is a forgotten tool these days and reemphasized it's utility in complementing smear diagnosis. We also observed better architecture in the form of well-developed keratin pearl on $\mathrm{CB}$ from a lymph node aspirate diagnosed as poorly differentiated carcinoma on CS. CB provided material for CK and EMA in another case of lymph node aspirate diagnosed as undifferentiated carcinoma/lymphoma on CS thereby improving the diagnosis to carcinoma. This highlights the role of $\mathrm{CB}$ in pre-operative diagnosis of metastatic cystic lesions.

Despite the expanding literature and increasing use of the technique, the role of aspiration of the ovaries is still controversial, with some authors suggesting that aspiration biopsy of the ovary (except for the purpose of oocyte retrieval) is potentially dangerous and should not be regarded as a routinely acceptable clinical practice. [24] The arguments against the use of FNA include the possible spillage of malignant cells into the abdominal cavity, leading to the potential dissemination of tumor, as well as misdiagnosis related to sampling errors. ${ }^{[25]}$ Having noted this opinion, it is important to point out that some of the literature also indicates that the use of needle aspiration of the ovary is valuable, safe, and even the standard of care in certain clinical settings, notably in young women who wish to preserve their ovarian function.

We aspirated 12 intact ovarian cysts sent to us for frozen section, before cutting them open to take bits. The aspirated fluid was processed for both $\mathrm{CS}$ and $\mathrm{CB}$. CB confirmed $\mathrm{CS}$ findings in eight benign cysts, bettered diagnosis in one (from ovarian leiomyoma with cystic degeneration to ovarian fibroma), where the $\mathrm{CB}$ gave additional material for smooth muscle actin (SMA) staining. Two cases were positive for malignancy in CS out of which CB gave better diagnosis by better architecture in one, but in the other case $\mathrm{CB}$ was non-contributory. In another ovarian cyst, suspicious for malignancy on $\mathrm{CS}$, the $\mathrm{CB}$ was non- contributory. Extrapolating this finding, may we suggest pre-operative USG guided aspirate of ovarian cyst with CBs to confirm their nature and plan for future surgical procedure? This appears promising especially in young women who wish to preserve their ovaries.

Panlanowitz et al in their study of utility of cell block preparation in cytologic specimens diagnostic oflymphoma, found cell block preparation of cytologic material extremely beneficial, with the potential for further reducing the need for surgical excision. ${ }^{[10]}$ Similar to our study, Mayall et al reviewed 50 consecutive cytology cell block preparation in a large general hospital. They concluded that the use of CBs are reliable and technically unsophisticated which aid in the cytological examination. ${ }^{[26]}$

Though CB complements CS diagnosis with added advantage of better architecture, availability of material for special stains and IHC in many cases, CB also has certain disadvantages. Delay in the diagnosis when compared to conventional smears due to additional time for $\mathrm{CB}$ preparation, ${ }^{[17]}$ risk of losing material during processing and increased cost are some of the drawbacks. ${ }^{[2]}$ Some authors like Wojick et al found that the additional studies of cell blocks is of little benefit after a study comparing CS and CB in recurrent gynecologic malignancies. ${ }^{[5]}$ 
Katharine et al ${ }^{[8]}$ when comparing the results of smears to those of cytospin and $\mathrm{CB}$ preparations (from fine needle aspirations from 844 superficial and deep seated lesions), to determine the cost effectiveness of each found that smears were superior to either cytospin or CBs in providing a diagnosis. However, they suggested that when the immediate smear evaluation is non-diagnostic, it is cost effective to obtain cell blocks. ${ }^{[8]}$ Saleh et al, in their study of comparison of thin-prep and cell block preparation for the evaluation of 126 thyroid epithelial lesions on fine needle aspiration biopsy concluded that thin-prep slide preparation is superior to cell block preparation and is more likely to have greater cellularity for diagnosis and detect atypical/ neoplastic thyroid lesions, particularly those of follicular cell origin. They also suggested thin-prep slides to be used as complementary to direct smears. ${ }^{[9]}$

Similarly in our study $18 / 50$ cases (36\%) CB was inadequate and in 3/50 (6\%) cases $\mathrm{CB}$ was noncontributory. Among these were 3 cases diagnosed as positive for malignancy $n$ and 2 suspicious for malignancy on $\mathrm{CS}$ but $\mathrm{CB}$ was false negative.

To address these short comings authors have suggested a dedicated needle aspiration for cell block improves yield. ${ }^{[17]}$ Mayall et al were of the opinion, that a highly experienced aspirator should perform FNA to obtain sufficiently cellular material for CB. ${ }^{[26]}$ With our experience of $\mathrm{CB}$ with cystic lesions, aspirates from multiple sites of the cyst pooled as one specimen showed good pellet formation and thereby adequate material on $\mathrm{CB}$. CB was diagnostic in aspirates done with radiological assistance (USG/CT).

In summary, $\mathrm{CB}$ method is an excellent complementary tool for improving cyto-diagnosis in aspirates of cystic lesions. Though CBs were complementary to CS in the overall categorization of benign and malignant groups, they appeared to be more useful in diagnosis of malignancy by better preserved architectural patterns, as seen in corresponding histopathology sections. Aspirates from multiple sites of cystic lesions, pooled as one specimen yielded good pellet formation and thereby adequate material on $\mathrm{CB}$. $\mathrm{CB}$ was diagnostic in aspirates done with radiological assistance (USG/CT). Thus $\mathrm{CBs}$ appeared to bridge cytology and histopathology along with providing excellent resource material for ancillary techniques like histochemistry and IHC.

\section{References}

1. Ansari NA, Derias NW. Fine needle aspiration cytology. J Clin Pathol 1997;50 : 41-3.

2. Khan S, Omar T, Michelow P. Effectiveness cell block technique in diagnostic cytopathology. $\mathrm{J}$ of Cytol 2012;29:177-82.
3. Karnauchow PN, Bounin RE. Cell block technique for fine needle aspiration biopsy. J Clin Pathol 1982;35:688.

4. Kung IT, Yuen RW, Chan JK. Optimal formalin fixation and processing schedule of cell blocks from the fine needle aspirates. Pathology 1989;21: 143-5.

5. Wojcik EM, Selvaggi SM. Comparison of smears and cell blocks in the fine needle aspiration diagnosis of recurrent gynecologic malignancies. Acta Cytol 1991;35:773-6.

6. Yang GC, Wan LS, Papellas J, Waisman J. Compact cell blocks. Use for body fluids, Fine needle aspirations and Endometrial brush biopsies. Acta Cytol 1998;42:703-6.

7. Zito FA, Gadaleta CD, Salvatore C, Filatico R, Labriola A, Marzullo A et al. A modified cell-block technique for fine needle aspiration cytology. Acta Cytol 1995;39: 93-9.

8. Liu K, Dodge R, Glasgow BJ. Fine needle aspiration: comparison of smear, cytospin and cellblock preparations in diagnostic and cost effectiveness. Diagn Cytopathol 1998;19:70-4.

9. Saleh HA, Hammoud J, Zakaria R, Khan AZ. Comparison of Thin-Prep and Cell block preparation for the evaluation of Thyroid epithelial lesions on fine needle aspiration biopsy. CytoJournal 2008;5-3.

10. Panlanowitz L, Freeman J, Goulart RA. Utility of cellblock preparation in cytologic specimens diagnostic of lymphoma. Acta Cytol 2010;54:236-7.

11. Oenning ACC, Rivero ERC, Calvo MCM, Meurer MI, Grando L J. Evaluation of the cell block technique as an auxiliary method of diagnosing jawbone lesions. Braz Oral Res 2012;26:355-9.

12. Rivero ERC, Grando LJ, Manegat F, Claus JDP, Xavier F. Cell block technique as a complementaty method in the clinical diagnosis of cyst-like lesions of the jaw. J Appl Oral Scin 2011;19:269-73.

13. Hegazy RA, Hegazy AA. FNAC and cell block study of thyroid lesions. Universal Journal of Medical Science 2013; 1:1-8.

14. Nguyen CK, Lee MW, Ginsberg J, Wragg T, Bilodeau D. Fine needle aspiration of the thyroid: an overview. Cyto Journal 2005;2:12.

15. Khurana KK, Ramzy I, Truong LD. p 53 immunolocalization in cell block preparation of squamous lesions of neck: an adjunct to fine needle aspiration diagnosis of malignancy. Arch Pathol Lab Med 1999;123:421- 5.

16. Xiao GQ. Fine needle aspiration of cystic pancreatic mucinous tumor: oncotic cells as an aiding diagnostic feature in paucicellular specimens. Diagn Cytopathol 2009;37:111-6.

17. Koss LG. Effusions in the absence of cancer. In: Koss LG, Melamed MR, editors. Diagnostic Cytology and its Histopathologic Basis, 5th edition, Philadelphia: Lippincott Williams \& Wilkins; 2006. p. 919-48. 
18. Nathan NA, Narayan E, Smith MA, Horn MJ. Cell block cytology: Improved preparation and its efficacy in diagnostic cytology. Am J Clin Pathol 2000;114:599-06.

19. Jain D, Mathur SR, Iyer V K. Cell blocks in cytopathology: a review of preparative methods, utility in diagnosis and role in ancillary studies. Cytopathology 2014;25:356-71.

20. Radhika S, Nijhawan R, Das A, Dey P. Ameloblastoma of the mandible: diagnosis by fine needle aspiration cytology. Diagn Cytopathol 1993;9:310-3.

21. Narayan SM, Padmini J, Parthiban R, Madhusmita J, Natarajan G, Revadi PS. Diagnosis of a case of papillarycystic variant of acinic - cell carcinoma on fine needle aspiration cytology: Myriad of cyto-morphological features. International Journal of Case Reports and Images 2014;5:18-22.
22. Kim AR, Park SJ, Gu MJ, Kim HJ. Fine needle aspiration cytology of hepatic hyadatid cyst: a case study. The Korean J Pathol 2013;47:395-8.

23. Dahima S, Hegde P, Shetty P. Cell Block a forgotten tool. J of Mol Path Epidemol 2015:1:1

24. Trimbos JB, Hacker NF. The case against aspirating ovarian cysts. Cancer 1993;72:828-31.

25. Sherman ME: Cytopathology. In: Kurman RJ (ed). Blaustein's Pathology of the Female Genital Tract, 4th ed. New York: Springer-Verlag;1994. p. 1120-22.

26. Mayall F, Chang B, Darlington A. A review of 50 consecutive cytology cell block preparations in a large general hospital. $\mathrm{J}$ Clin Pathol 1997;50:985-90.

*Corresponding author:

Dr S R Niveditha, Department of Pathology, Kempegowda institute of Medical sciences, Banashankari 2nd stage, Bangalore - 560070, India

Phone: +919845485544

Email: srniveditha@gmail.com

Date of Submission : 03.01.2017

Date of Acceptance : 02.02.2017

Financial or other Competing Interests: None.

Date of Publication : 14.04.2017 